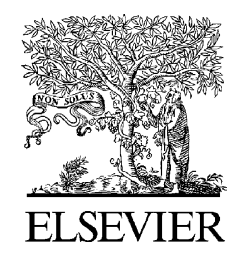

\title{
EDITORIAL
}

\section{Asthma deaths - are we doing enough?}

Asthma is usually considered a relatively benign and reversible disease by both health professionals and the lay community. Therefore the paper by Harrison et al. in this issue [1] is a timely reminder that asthma can have fatal outcomes. Within the paper there are many points that act as indicators of management issues which have been repeatedly highlighted by previous reviews of asthma deaths $[2,3]$. The description of this UK Eastern Region Confidential Enquiry into asthma deaths describes a very important review process of disease outcomes and of management practice hal contains messages for all cliniciane ara for policy makers involved in asth in care.

The messaje: include.

- Most fatal attacks are not of severe sudden onset and therefore the opportunity for intervention exists.

- People who have been assessed as having mild asthma can have a fatal asthma attack.

- Asthma deaths usually involve a range of trigger factors or psychosocial factors being present in the same individual to result in the fatal attack.

- Areas of management that need to be addressed by health bureaucrats and health professionals include;

- The policy for follow up of those who have had a signal event such as a hospital admission who and how?

- The development of "at risk" registers to ensure appropriate continuing management.

- Death certificates have a high false positive rate for asthma deaths even in the under-65 age group.

- Asthma deaths have fallen in recent years.
Can this data be extrapolated beyond the study region in which it was conducted? The answer is likely to be yes, and the following examples from Australia illustrate the strong likelihood.

The Asthma in Australia 2005 report [4] documents that there has been a fall in asthma mortality rates measured in numbers of deaths per 100,000 of population. In the all-age mortality of deaths due to asthma there nis been a progressive decline, from 1988 Vinen $i$ was above 4.5 deaths rerceo,jod of population for both males and fernales, to 200? When it was 1.7 deaths per 100,000 tpr indates and 2.2 deaths per 100,000 for fe riales. Even the 5-34 year age group, where the diagnosis of asthma is likely to be most accurate, shows similar trends with lower levels as compared to the all-age group. In Australia in 1989, 736 asthma deaths were documented on the basis of death certificate reporting and there has been a decline to 314 deaths in 2003. The majority of the deaths reported in Australia are in the 65-andover age group. As indicated in the UK Eastern Region report [1] there are likely to be a large number of false positives, particularly when other co-morbid features are present. However, there is a note of caution, since there must also be a false negative rate in the reporting of asthma deaths by death certificates. The false negative rate is likely to be higher in an older person since the level of undiagnosed asthma in older patients is thought to be higher [5]. How the false positive and false negative figures balance out is uncertain, but there is still the clear concern that asthma deaths are occurring when there are preventable features. The Enquiry findings [1] are similar to those found in Australia by Campbell et al. [2], and 
the interaction of psychosocial factors and asthma deaths are similar to those reported in a Victorian study recently [6]. Therefore it seems reasonable to think that the UK Eastern Region Confidential Enquiry findings can be applied in countries with similar standards and health service delivery to the UK.

This Confidential Enquiry [1] also indicates that the management of asthma can be very complicated. It may be relatively simple to manage the large proportion of people with mild asthma. However, the identification of those people "at risk" with severe asthma or with difficult asthma [7] is important, and this is where the management of asthma becomes complex. The concept of an asthma patient being "at risk" is possibly better than mixing terminology of "severe" and "difficult" asthma which may confuse health professionals - in particular, does the term "severity" refer to an acute episode or the chronic stable state? The impact of terminology on patients, patient behaviour, and health professional behaviour, is an area which deserves more research including qualitative research.

There are many aspects of asthma management that overlap with chronic disease management. An example of the complexity and the difficult:y of asthma management is in the use of ation plans in self-management of astinal The use of individua/ised plats bas been supperced by evidence-bastú reviews [8]. How ver, in Australia, action plan ownership by asthmatics in a population survey has halved over the last ten years [9]. Despite this, asthma deaths have continued to fall [4]. It may be generously interpreted that the action plans have therefore been appropriately targeted to those "at risk", or sceptically interpreted that the plans have not been individualised. The complexity of asthma management means that treating clinicians should know whether or not individual patients are able to perceive symptoms, and secondly, whether they are willing to be an active decision maker and to initiate change in treatment without consulting a doctor [10]. The complexity of management means that more time and more skills are required from health professionals for the "at risk" asthma patient.

The Enquiry [1] suggests the development of "at risk" registers to facilitate and formalise continuing management. The support of the registry by multidisciplinary management teams [7], specific help for a proportion of the patients by coaching, and negotiating management, are potential important features of an altered approach to management. The resources required to initiate such an approach are large and the idea would probably need to be sold to policy makers on the basis of: evidence from pilot studies; linkage to wider chronic disease management programs; and prospective evaluations of cost benefit for the community at fixed intervals. There is some evidence to support individualised and multidisciplinary management as summarised in a recent review by Harrison [7].

We need to convince policy makers that such changes to service delivery are required to reduce the preventable asthma death burden. We do not need more confidential enquiries until there have been system changes made. Enough evidence exists to show that practice changes need to be made. When the changes have been broadly enacted, it will be time to audit and review asthma deaths by confidential enquiry again. In the meantime we should monitor asthma deaths via death certificate notification, but remain aware of the weaknesses in the methodology.

\section{$\mathrm{Re}$}

[1] Harrisol B, Stepherson P, Mohan G, Nasser S. An ongoing Corfidential Enquiry into asthma deaths in the Eastern Fegion of the UK. Prim Care Resp J 2005;14(6):30313.

[2] Campbell DA, McLennan G, Coates JR, et al. A comparison of asthma deaths and near-fatal asthma attacks in South Australia. Eur Respir J 1994;7:490-7.

[3] Wareham NJ, Harrison BDN, Jenkins PF, Nicholls J, Stableforth DE. A district confidential enquiry into deaths due to asthma. Thorax 1993;48:1117-20.

[4] AlHW Australian Centre for Asthma Monitoring 2005. Asthma in Australia 2005. AlHW Asthma Series 2 AlHW Cat No. ACM6 Canberra: AlHW.

[5] Adams RJ, Wilson DH, Appleton S, et al. Under diagnosed asthma in South Australia. Thorax 2003;58:84650.

[6] Barton CA, McKenzie DP, Walters EH, Abramson MJ, The Victorian Asthma Mortality Study Group. Interactions between psychosocial problems and management of asthma: who is at risk of dying? J Asthma 2005;42:24956.

[7] Harrison BD. Difficult asthma in adults: recognition and approaches to management. Intern Med J 2005;35:543-7.

[8] Gibson PG, Powell H. Written action plans for asthma: an evidence-based review of the key components. Thorax 2004;59:94-9.

[9] Wilson DH, Adams RJ, Appleton SL, et al. Prevalence of asthma and action plans in South Australia: population surveys from 1990 to 2001. Med J Aust 2003;179: 483-5.

[10] Adams RJ, Smith BJ, Ruffin RE. Patient preferences for autonomy in decision making in asthma management. Thorax 2001;56:126-32. 
Richard Ruffin (Michell Professor of Medicine) Department of Medicine, TQEH Campus, Adelaide University, 28 Woodville Road,

E-mail address: richard.ruffin@adelaide.edu.au

30 September 2005 Woodville, South Australia, 5011 Australia

Available online at www.sciencedirect.com science $\boldsymbol{d}$ Direct.

Available online at http://www.thepcrj.com

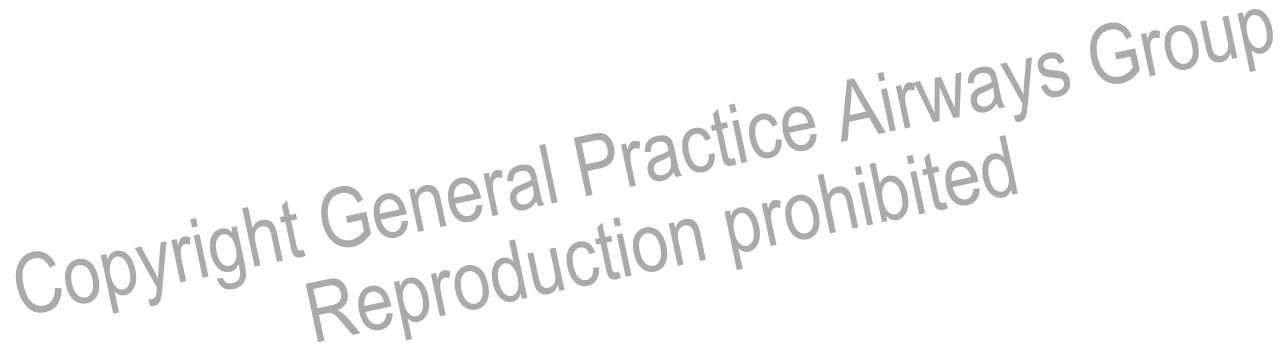

